\title{
Research progress on surface antigen 1 (SAG1) of Toxoplasma gondii
}

\author{
Yanhua Wang ${ }^{*}$ and Hong Yin
}

\begin{abstract}
Toxoplasma gondii is an obligate intracellular parasitic protozoan that has a wide host range and causes a zoonotic parasitosis called toxoplasmosis. This infection causes significant morbidity, costs for care and loss of productivity and suffering. The most effective measures to minimize this parasite's harm to patients are prompt diagnosis and treatment and preventing infection. A parasite surface antigen, SAG1, is considered an important antigen for the development of effective diagnostic tests or subunit vaccines. This review covers several aspects of this antigen, including its gene structure, contribution to host invasion, mechanisms of the immune responses and its applications for diagnosis and vaccine development. This significant progress on this antigen provides foundations for further development of more effective and precise approaches to diagnose toxoplasmosis in the clinic, and also have important implications for exploring novel measures to control toxoplasmosis in the near future.
\end{abstract}

Keywords: T. gondii, Surface antigen 1, Gene structure, Invasion, Diagnosis, Vaccine

\section{Review}

\section{Background}

Toxoplasma gondii is an obligate intracellular parasitic protozoan that is globally distributed, has a wide host range and causes zoonotic parasitosis [1,2]. T. gondii is an opportunistic infective agent and may cause death in individuals with compromised or suppressed immune functions, e.g., patients who suffer from AIDS (acquired immunodeficiency syndrome) or cancer or who have undergone organ transplantation. In addition, toxoplasmosis can have significant effects on reproduction because, if a pregnant woman is infected with T. gondii, maternal-fetal vertical transmission may occur and result in miscarriage, stillbirth or congenital defects or deformities (e.g., malformation, retardation, etc.) in infants regardless of the presence of clinical symptoms in the mother [3-5]. Moreover, the parasite also causes tremendous problems for livestock husbandry as the infection may lead to abortion and stillbirth in pregnant animals [6-8], especially cattle, goats and sheep [9], and high mortality rates in swine populations [10].

\footnotetext{
*Correspondence: wangyh061001@163.com
State Key Laboratory of Veterinary Etiological Biology, Lanzhou Veterinary
Research Institute, Chinese Academy of Agricultural Sciences, Lanzhou

* Correspondence: wangyh061001@163.com
State Key Laboratory of Veterinary Etiological Biology, Lanzhou Veterinary
Research Institute, Chinese Academy of Agricultural Sciences, Lanzhou

* Correspondence: wangyh061001@163.com
State Key Laboratory of Veterinary Etiological Biology, Lanzhou Veterinary
Research Institute, Chinese Academy of Agricultural Sciences, Lanzhou 730046, China
}

The tachyzoite is the key disease-causing form. During the acute stage of infection, tachyzoites activate a potent host immune response that eliminates most of the parasites. The surface of the tachyzoite is the main target of the host immune response. SAG1 is a major surface antigen involved in this process. Although it only accounts for $3-5 \%$ of total $T$. gondii protein, the majority of the antibodies are reactive against SAG1 during infection [11]. Various SAG1 preparations purified from the parasite $[12,13]$, produced by recombinant systems in Escherichia coli [14] or yeast [15] and its constituent peptides [16-18], have all been demonstrated to stimulate host humoral and cellular immunity, thereby providing protection against toxoplasmosis [19]. As such, SAG1 features excellent antigenicity and immunogenicity and is valuable for both diagnosis and immunization. This article comprehensively evaluates the research progress on SAG1.

\section{Gene structure of SAG1}

In 1980, Handman et al. [20] first identified SAG1 from $T$. gondii surface membrane antigens using a monoclonal antibody technique. Subsequently, Kasper et al. [21] applied mAb-affinity chromatography to isolate the protein. In 1988, Burg et al. [22] cloned the complete $T$. gondii sag1 gene, which has a length of $1.1 \mathrm{~kb}$, encodes 336 amino acids and yields a $30 \mathrm{kDa}$ protein. In $T$. 
gondii, SAG1 anchors to the cell membrane by a glycosylphosphatidylinositol anchor. Sag1 is a single-copy gene that does not have introns in the coding region or a TATA box in the promoter region. SAG1 transcription is governed by five 27-bp repeat sequences 35-190 bp upstream of the first two transcription start sites, and these repeat elements play a selective role in determining the transcription initiation site [23]. The repeat number of the conserved sequence is associated with the virulence of different T. gondii strains [24]. Specifically, highly virulent strains have five intact 27 -bp repeats located 70 bp upstream of the transcription initiation site, whereas less virulent strains have only four repeats; additionally, the sag1 expression level in virulent strains is over 4 times higher than that in avirulent strains. Sequence analysis of SAG1 cDNA revealed that 2 ATGs could function as the start codon and in turn generate signal sequences of 47 amino acids or 30 amino acids. Translation of sag1 is generally accepted to begin with the second ATG codon, although both codons can be used to artificially start SAG1 synthesis. The nascent polypeptide resulting from a primary SAG1 mRNA transcript contains hydrophobic regions in both the $\mathrm{N}$ - and C-termini that are not present in most mature SAG1 proteins on the surface of $T$. gondii. However, the $\mathrm{N}$ terminal hydrophobic region is believed to play a role in surface transport of the protein. After translocation, the signal peptide and the $\mathrm{C}$-terminal hydrophobic region are cleaved and glycosylated, forming the mature SAG1 protein, which is anchored to the $T$. gondii cell surface. Although sag1 sequences from different strains are highly similar, the gene contains polymorphisms, as evidenced by differences in SAG1 between the RH and ME49 strains at the amino acid level and the sag1 gene sequence of ME49 strain being identical to that of the CEP strain except for a difference in the non-coding sequence $[22,25,26]$.

Roles of SAG1 in the invasion of $T$. gondii into host cells T. gondii parasitizes not only phagocytes but also various non-phagocytic cells. Because this protozoan lacks several specific organelles, including flagella, cilia and pseudopodia, to facilitate invasion, multiple "receptorligand" interactions between the parasite and host cells exist. SAG1 has been demonstrated to be a crucial $T$. gondii ligand in promoting invasion of tachyzoites into host cells and allowing tachyzoite binding to host receptors. In vitro antibody neutralization experiments have revealed that a monoclonal anti-SAG1 antibody can partially block the invasion of tachyzoites into host cells [27-29]. Additionally, soluble SAG1 can directly bind to the host cell surface. The surface of SAG1 contains a groove to accommodate its dimerization. The groove region of the SAG1 dimer extends outwards from the cell surface and can effectively bind to its cognate ligands on the host cell surface [30]. Robinon et al. [31] demonstrated that soluble BSA-glucosamide blocks SAG1 attachment to MDBK (adult bovine kidney; Madin \& Darby) cells using a competitive binding approach. Although anti-SAG1 antibodies and BSA-glucosamide inhibit tachyzoite attachment in vitro, it is not known whether their blocking effects are explicitly mediated through masking host cell binding domains on SAG1.

Conformational changes of SAG1 can influence Toxoplasma adherence to host cells [28]. For example, the sag1 of the wild-type PLK strain is predicted to encode 9 cysteine residues, whereas the mutant strains PTgA or $\mathrm{PTgC}$ harbor mutations at the cysteine sites that cause protein misfolding and in turn diminish $T$. gondii adherence to human fibroblasts by $26 \%$ or $39 \%$. T. gondii invasion into host cells is dependent on multiple factors. Two of these factors, SAG2 and SAG3, are in the vicinity of SAG1 on the T. gondii cell membrane and can assist SAG1 in facilitating rapid parasite invasion. Similar to sag1, sag2 is also a member of a gene family, and these two gene families share weak homology. Furthermore, Tomavo [32] discovered that SAG3 also has a pivotal role in the invasion of $T$. gondii tachyzoites. SAG1 and SAG3 share $24 \%$ amino acid sequence identity, 12 cysteine residues and some identical short peptides [33]. These findings indicate that although $T$. gondii tachyzoites produce a variety of surface membrane proteins, the major ones share many similarities (e.g., sequence, function), suggesting that they may have evolved from a single ancestral protein. Nevertheless, interactions between these membrane proteins remain to be characterized.

\section{Relationship between sag1 and strain virulence}

To elucidate the relationship between sag1 and T. gondii virulence, Howe et al. [34] examined the sag1 locus from parasite lineages of varying virulence. Through digestion with three restriction enzymes and hybridization using specific nucleic acid probes, the P89, G622-M and ROD strains were found to share a restriction pattern with the sag1-1 allele, which is a hallmark of the RH strain. In addition, the restriction pattern of another allele in the locus, sag1-2, was different, and this allele has only been found in CEP, a strain that is widely recognized to have weak virulence. These results appeared to indicate that P89, G622-M and ROD were all virulent strains, although animal experiments showed that P89 and G622-M exhibited a similar virulence level to that of CEP; all three strains had the same $100 \%$ lethal dose (LD100) of 10,000 tachyzoites and the same LD50 of 100 tachyzoites. However, ROD, a recombinant strain, displayed a potent toxicity to mice with an $\mathrm{LD}_{100}$ of 100 tachyzoites and a $60 \%$ lethal dose of 10 tachyzoites [34]. It can therefore be concluded that $T$. gondii strains with the same sag1 allele may 
still exhibit different virulence phenotypes, suggesting that the locus has a negligible effect on T. gondii virulence. These results can also be interpreted as these phenotypic differences being caused by the sequences flanking sag1. Hence, Howe et al. [34] used a 9-kb ClaI-EcoRI genomic fragment to probe pre-digested genomic DNA samples, and the subsequent Southern blot revealed that the RH strain displayed the same pattern as P89, G621-M and ROD and was different from that of CEP. This result appeared consistent with the virulence difference between the RH and CEP strains.

In addition, $P v u I I$ digestion of the Southern blot samples revealed that both virulent strains, $\mathrm{RH}$ and ROD, had a PvuII site, which was not found in either P89 or G622-M. Further experiments showed that the PvuII site resides $1 \mathrm{~kb}$ upstream of the sag1 locus, which was afterwards also corroborated by Lekutis et al. [35]. In the latter study, Lekutis et al. used the gene for hypoxanthinexanthine-guanine phosphoribosyltransferase to generate a mutant lacking sag1 by homologous recombination into the T. gondii genome. With the extension of in vitro culture time, the mutant displayed an invasive capacity 2 -fold higher than that of the wild-type $\mathrm{RH}$ strain. However, when parasites were intraperitoneally inoculated into Swiss Webster mice, the mutant-infected group had a delayed acute-phase death compared to the $\mathrm{RH}$-inoculated animals, indicating that the mutant was less virulent than the wild-type. Taken together, studies have indicated that the presence of allele 1 at the sag1 locus is not alone sufficient to confer acute virulence, which is dictated by the sag1 gene per se as well as by its flanking regions, especially the upstream sequences.

\section{Studies on SAG1 epitopes}

A protein antigen does not require its intact molecule to generate antigenic effects; rather, the molecule produces the specific effects via individual epitopes [36]. Moreover, a protein antigen not only contains epitope structures closely related to immune recognition by $\mathrm{B}$ cells, $\mathrm{T}$ cells and NK cells but also harbors some elements that are unfavorable for protective immunity. As such, to improve the protective traits of a protein antigen, choosing proper epitope levels is necessary to eliminate deleterious components and retain advantageous elements [36]. Such studies on antigen epitopes of SAG1 have been conducted [11,25,37-41].

Nam et al. [25] reported that the antigenicity of SAG1 is primarily controlled by a $1 / 3$ to $4 / 9$ region from the $\mathrm{N}$-terminus. Godard et al. used a mouse model in conjunction with sequence prediction and peptide scanning to identify 3 antigenic peptides (i.e., $48-67$ aa, 238-256 aa and 279-285 aa). They concluded that the C-terminus was the dominant antigenic and immunogenic region and that the 238-256 aa peptide was also an important $\mathrm{T}$ cell epitope [11]. Begheto et al. used sera from toxoplasmosis patients to screen a cDNA phage display library of $T$. gondii and discovered that the C-terminus of SAG1 displayed stronger reactivity to the sera [37]. Likewise, Siachoque et al. examined the B cell epitopes of SAG1 and revealed that they were primarily concentrated near the C-terminus using a mouse model and peptide scanning [38]. Furthermore, Cardona et al. [40] used peptide scanning to investigate the B cell epitopes of SAG1 and discovered that in addition to several C-terminal fragments (181-200 aa, 241-260 aa, 261-280 aa and 301-320 aa), the sera of $T$. gondii-infected individuals recognized an Nterminal fragment (61-80 aa), although the 301-320 aa had the highest reactivity. Similarly, our laboratory used sera from T. gondii-infected pigs to screen B cell epitopes of SAG1 and showed that fragments composed of 91-120 aa, 151-180 aa, 271-300 aa and 301-336 aa were all specifically recognized by the porcine sera and that the 271300 aa fragment displayed the strongest reactivity [41]. A comprehensive analysis of the above findings indicated that the sera from $T$. gondii-infected humans and pigs and SAG1-immunized mice exhibited some differences in serum recognition patterns. Fine mapping of antigenic epitopes could advance the development of diagnostic reagents and epitope vaccines for $T$. gondii.

\section{Mechanisms of the immune responses induced by SAG1}

The SAG1 protein is abundant in tachyzoites and is highly immunogenic. Therefore, this protein can stimulate the host to generate relevant humoral and cellular immunity. Humoral immunity plays a role in countering $T$. gondii infection, but cellular immunity is the major mechanism whereby SAG1 induces the host to generate immune protection. This process requires different types of $\mathrm{T}$ lymphocytes (e.g., $\mathrm{CD} 4^{+}, \mathrm{CD}^{+} \mathrm{T}$ cells) coordinated by many cytokines, including IFN- $\gamma$, IL- 2 and TNF-a, and plays a crucial role in host anti- $T$. gondii protective immunity [42]. CD8 ${ }^{+} \mathrm{T}$ cells are the primary cell subpopulation that acts against $T$. gondii infection of target cells, and their cytotoxicity is antigen-specific. Once immunized, mice displayed elevated SAG1-specific $\mathrm{CD}^{+}{ }^{+} \mathrm{T}$ cells and acquired an almost complete ability to counter acute $T$. gondii infection. Although $\mathrm{CD}^{+} \mathrm{T}$ cells do not require the assistance of $\mathrm{CD} 4^{+} \mathrm{T}$ cells to exert an immune protective effect, the presence of IFN- $\gamma$ is essential for this event, and the anti-T. gondii function of $\mathrm{CD} 8^{+} \mathrm{T}$ cells is unaffected by the removal of $\mathrm{CD} 4^{+} \mathrm{T}$ cells but disappears without IFN- $\gamma$. In addition to $\mathrm{CD}^{+} \mathrm{T}$ cells, activated macrophages also participate in a host's anti-T. gondii activities [43].

\section{Vaccines based on SAG1 of $T$. gondii \\ Gene deletion attenuated vaccine}

Increased knowledge of T. gondii at the molecular level, greatly facilitated by the completion of the genome 
project, in combination with rapid progress in the development of genetic tools to manipulate the parasite, has generated opportunities to create new attenuated vaccines [44]. SAG1 of Toxoplasma has also been targeted for deletion and two types of SAG1 mutants have been generated. One was made by chemical mutagenesis and the other was recently genetically engineered $(\Delta s a g 1)$. Both attach to, enter, and proliferate at approximately normal rates within host cells $[28,45,46]$. $\Delta$ sag1 tachyzoites were lethal in susceptible C57BL/6 mice (although survival was slightly prolonged compared with wild-type infected mice), but deletion of sag1 prevented an acute ileitis when tachyzoites were directly injected into the intestine. At present, the infectivity of Toxoplasma mutants that have been generated by reverse genetics has only been analyzed in mice and not in larger animals. In past years, various Toxoplasma gene deletion mutants have been generated although the objective has usually been to gain further insight into the function of a particular gene rather than to generate a vaccine. However, it is likely that any biologically important gene will contribute to the fitness and/ or virulence of the parasite, and consequently the vaccine potential of these mutants has been of significant interest.

\section{Subunit vaccines}

Subunit vaccines have the advantage that specific immunogenic antigens are presented without adding antigens that are at best irrelevant and at worst capable of inducing febrile or disease-exacerbating immune responses. SAG1 vaccines for T. gondii have been studied extensively with promising results. To produce the vaccine, SAG1 antigen purified via a monoclonal antibody is used to immunize mice [13] to induce cytotoxicity of CD8+ cells, thereby generating high levels of IFN- $\gamma$ and IL- 2 and a protective immunity that combats acute and chronic infection. Due to the high cost of purifying tachyzoite membranes, molecular cloning has replaced this technique. Makioka et al. [47] PCR amplified the SAG1 gene, cloned it into several vectors, including pTV118N, pKK233-2 and pGEX-1, and transformed it into several E. coli strains (JM109, JM105, etc.). Among these combinations, the pGEX-1 recombinant plasmid achieved a high expression level using a GST (glutathione S-transferase)-fusion protein. This recombinant protein has been demonstrated to be able to activate macrophages in animal experiments and to exhibit toxoplasmacidal effects in in vitro assays. More importantly, macrophage activation was shown to be caused by SAG1, not the GST tag, in the fusion protein. In addition, SAG1, adjuvant withstanding, has induced comparatively good protection in terms of limiting maternofetal transmission [48].

Although subunit vaccines are safer than inactivated whole-cell or live attenuated vaccines, they have weak immunogenicity and are not effectively recognized and presented by antigen-presenting cells. Hence, development of subunit vaccines for $T$. gondii requires not only antigen optimization but also adjuvants to boost immunogenicity and induce generation of immune-active compounds. With optimized antigens in combination with effective adjuvants, the resulting vaccines can modulate the intensity and types of immune responses and produce effective and long-lasting protective immunity [49].

\section{Bacterial and viral vector vaccines}

Live bacterial vaccine vectors have been extensively used to deliver and express heterologous vaccine antigens to protect against cancer and various infectious agents, including AIDS. Live bacterial vaccines have the advantage that they can express multiple antigens, are easily mass produced, can be orally or intranasally applied, and induce strong immune responses. However, relatively few studies have tested whether heterologous expression of parasitic antigens with bacterial vaccine vector strains can lead to protective immunity. For example, oral immunization with a live attenuated Salmonella typhimurium vaccine strain was used to protect mice against T. gondii [50]. SAG1 and SAG2 were delivered with a eukaryotic expression plasmid which also contained cholera toxin (CT) subunits A2 and B. CT is known to have an adjuvant effect, and indeed the addition of $\mathrm{CT}$ subunits A2 and B induced a strong cellular immune response, as measured by induced specific IgG2a titers, splenocyte proliferation, and IFN- $\gamma$ production. Upon challenge with $1000 \mathrm{RH}$ tachyzoites the vaccinated mice survived longer, and 40 percent of the mice survived the whole trial period. Whether this vaccine could prevent tissue cyst formation and reduce cyst burden is unknown.

Although viral delivery of immunogenic antigens has been tested widely against various cancers and infectious diseases, including malaria, only a few studies have used this technique to express Toxoplasma antigens [44,51]. Vaccinations with viral vectors carrying Toxoplasma antigens have met with limited success. Lack of protection is either due to an improper immune response, and/or because non-protective antigens have been expressed.

\section{Nucleic acid vaccines}

Nucleic acid vaccines were developed in the 1990s and are the third generation of vaccine after pathogen vaccines and subunit vaccines. DNA vaccines are simple to prepare and are low-cost. Thus, they are conducive to large-scale industrial production. These molecules are expressed in the eukaryotic environments of host cells; therefore, the products are similar to the conformation of the natural counterparts and are able to induce more effective immune responses against the target protozoan 
[52]. In addition, persistent immune responses also simplify the immunization procedure. A Japanese group attempted an intradermal injection using a gene gun to introduce a SAG1-encoding plasmid into mice then used the skin from the inoculation site to perform an allograft. The results demonstrated that the inoculated skin could stimulate the body to generate protective antigens that effectively prevented a lethal $T$. gondii infection [53]. Likewise, Nielsen et al. [54] immunized animals with the p1tpA-SAG1 plasmid, which yielded an $80-100 \%$ survival rate for $\mathrm{RH}$-infected animals, whereas the control group, treated with the empty $\mathrm{p} 1 \mathrm{tpA}$ vector, displayed a $20 \%$ survival rate, showing that direct immunization with the pltpA-SAG1 plasmid can generate remarkable protection against infection. Nucleic acid vaccines promote not only the generation of humoral and cellular immune cascades but also the induction of local immune responses and immune memory [55]. In addition, nucleic acid vaccine vectors also contain non-coding immunostimulatory sequences that have an immunoadjuvant function and can act on various types of immune cells to effectively generate Th1 responses [43].

\section{Multivalent vaccine}

SAG1 is a stage-specific protein in T. gondii that is only present in tachyzoites but not bradyzoites. Monovalent SAG1 vaccines have been shown to yield only partial protection in test animals [56]. Hence, in the course of researching $T$. gondii vaccines, a consensus to develop multivalent vaccines that contain a combination of several antigens and target different developmental stages has been reached with the aim of overcoming the drawback of the monovalent candidate vaccines [57]. In this regard, SAG1 and ROP2 act synergistically during parasite invasion of host cells. As a consequence, the corresponding antibodies significantly block the infection of T. gondii. Alberto et al. immunized mice with a mixture of the pcDNA3/SAG1 and pcDNA3/ROP2 plasmids, which produced a Th1 immune response, proliferation of specific T cells, and a high IFN- $\gamma$ titer. Likewise, immunization with a plasmid mixture was shown to induce enduring protection against infection with the RH strain, whereas the control cohort treated with a monovalent gene vaccine was not resistant to the infection [58].

Extracting and purifying a combination gene vaccine is a complicated process that is worsened by the fact that eukaryotic cells accept a limited quantity of foreign DNA. Furthermore, expression of foreign genes from several plasmids inevitably causes competition in the host gene expression system. As such, complex gene vaccines have become a focus of research. The effectiveness of SAG1 DNA vaccines was generally enhanced by utilizing cocktail vaccines comprising of other antigens [9,58-63]. Additionally, we also support the view that relatively short peptides containing B- and T-cell determinants can be highly immunogenic, and therefore may be considered suitable alternatives in subunit vaccine design. In our laboratory, we investigate murine immune responses to one linear B-cell epitope (derived from conserved regions of SAG1) when conjugated to two other defined T-cell epitopes (from conserved regions of GRA1 and GRA4) in a MAP arrangement. Immunization of BALB/c and Kunming mice with the MAP construct in Freund's adjuvant induced not only a humoral immune response but also a cellular response. These responses were accompanied by significant levels of splenocyte proliferation and IFN- $\gamma$ in vitro. After lethal challenge, vaccinated mice had increased survival time in comparison to unvaccinated controls [61].

Taken together, studies have indicated that immune protection of SAG1 is influenced by multiple factors. Adjuvants play an important role in the efficacy of immunizations. It is the general consensus of opinion that a type- 1 response, particularly associated with $\mathrm{CD} 8+\mathrm{T}$ cells producing IFN- $\gamma$, is the major mediator of immunity against $T$. gondii infection. Interestingly, vaccination with the Th2-inducing adjuvant ALUM incorporating SAG1 was able to promote survival of BALB/c mice infected with virulent parasites [14]. Other important factors in immunization experiments are the selection of animal model (species/strain) and the selection of $T$. gondii strain. For example, subcutaneous SAG1 vaccination protected guinea pigs [64] and BALB/c mice [48] against maternofetal transmission, but failed to protect CBA/J mice [48]. As mice are normally susceptible to $T$. gondii infection, parasite strains with low virulence or low doses of virulent strains may be preferentially selected by some researchers [65]. In some studies of immunization, oral challenges were made with cystogenic strains [66]. It is important to point out that unnatural routes of infection may be key determinants of mouse survival.

\section{Application of SAG1 in the diagnosis of toxoplasmosis SAG1-based ELISA diagnosis}

T. gondii is an opportunistic protozoan parasite. The isolation of the parasite by mouse bioassay is often difficult as the procedures are time-consuming, laborious and inefficient. As such, the serological approach is currently the most common diagnostic method [67-69]. Among various known antigens, SAG1 has potent immunogenicity and immune-reactivity; therefore, it is not only significant for vaccine research but is also widely applied in diagnostics [70-72].

The antigens used for ELISA detection are mainly parasite, excreted/secreted, recombinant or multi-epitope antigens. Parasite antigens and excreted/secreted antigens contain complex ingredients and are difficult to standardize quantitatively and qualitatively; therefore, the relevant 
diagnostic systems tend to vary in detection efficiency [73-76]. SAG1 is a main surface antigen of T. gondii that induces high titers of IgG, IgM and IgA despite only accounting for $3-5 \%$ of total cellular proteins [19]. In addition, this protein is also a tachyzoite-specific antigen and is highly conserved [22]. Thus, it is important for diagnostic purposes [38,77]. Several groups have attempted to use recombinant DNA technology to prepare $T$. gondii SAG1 recombinant antigens, most of which, unfortunately, produce insoluble forms and lose antigenicity due to misfolding. Although the material can be refolded to partially recover the antigenicity, the procedure is extremely inefficient (5-8\%) and time consuming [78]. To address this issue, Wu et al. [79] tried different expression vectors and optimized expression conditions to express a truncated $S A G 1$ gene and obtained soluble recombinant protein, thereby establishing an ELISA diagnostic based on recombinant SAG1. This ELISA kit could be used to detect $T$. gondii infection sensitively and specifically. By comparison with the gold standard (the Western blot), the sensitivity and specificity of this ELISA kit is $93.9 \%$ and $100 \%$, respectively, whereas the efficiency is also better than the 2 commercially available ELISA kits constructed from the whole parasite extracts. The results confirmed that the recombinant SAG1 protein is an ideal diagnostic antigen for the development of diagnostic kits for human toxoplasmosis. However, the exact composition and association of recombinant antigens to be used in immunoassays to detect Toxoplasma antibodies are still open questions. Using the B-cell epitopes of those antigens for the serodiagnosis of toxoplasmosis has been found to present several advantages, such as the precise knowledge of the composition of the diagnostic antigen, the ability to use more than one identified B-cell epitope, and easy standardization of the method. The multiepitope chimeric antigen including SAG1 is one of the most promising antigens for the development of diagnostic kits for routine toxoplasmosis screening [80]. Of course, the application of multi-epitope antigens is largely dependent on identifying antigenic epitopes and solving technical details involved in their design. These issues include identifying B cell epitopes and T cell epitopes, identifying optimal combinations of different $B$ cell epitopes or $\mathrm{B}$ cell and $\mathrm{T}$ cell epitopes and avoiding new antigenic epitopes.

\section{SAG1-based molecular diagnostic methods $P C R$}

Because PCR sensitivity is closely linked to the copy number of the amplified gene, the $B 1$ gene, which has 35 copies and 200-300 repeats of a 520 bp fragment, is often used as a target gene [81-85]. However, the sensitivity of PCR is not only affected by the genomic copy number of the target gene but is also affected by the infection stage. Contini et al. [86] argued that for HIV patients, especially those that have undergone anti- $T$. gondii treatment, PCR targeting the $B 1$ gene is often negative. In contrast, PCR detection using primers specific to several target genes including sag1, sag4 and mag1 is often very effective. Savva et al. [87] first used PCR detection based on SAG1-specific primers and showed that they were able to amplify DNA from all of the seven test $T$. gondii strains but produced no bands from other parasites or microbes. Hence, these primers are highly specific. Hollman et al. extracted DNA from heart transplant biopsy specimens of 15 antibody positive subjects, and the DNA samples were used to amplify sag1, which identified 8 samples as positive [88]. In comparison, histology only identified 2 samples as positive, indicating that sag1-based PCR is clearly better than a histological approach.

\section{Loop-mediated isothermal amplification (LAMP)}

LAMP is a simple technique that rapidly amplifies specific DNA sequences with high sensitivity under isothermal conditions [89]. LAMP products can easily be detected by the naked eye due to the formation of magnesium pyrophosphate, a turbid white by-product of DNA amplification that accumulates as the reaction progresses. In addition, LAMP products can be detected by direct fluorescence. Other fluorescent dyes, such as ethidium bromide, SYBR green and Evagreen, have also been used for visualization of LAMP products. Furthermore, Thekisoe et al. have reported that LAMP reagents are relatively stable even when stored at 25 or $37^{\circ} \mathrm{C}$, which supports the use of LAMP in field conditions and resource-poor laboratories [90]. Recently, LAMP assays targeting the sag1 gene have been developed, and these methods were found to be powerful diagnostic tools [91-93].

\section{Conclusions}

SAG1 has been a focus of study because it is among the first few proteins that interact with host cells and is primarily involved in adhesion, signal transduction, invasion, material transport and host immune responses. Thus, this protein may be crucial for both the diagnosis of $T$. gondii infection and the ability to immunize against this parasite. This exciting progress on SAG1 will lay a solid foundation to combat toxoplasmosis.

Competing interests

The authors declare that they have no competing interests.

Authors' contributions

YHW and HY drafted the manuscript. Both authors read and approved the final manuscript.

Acknowledgments

This investigation was supported by grants from NBCITS, MOA (CARS-38). 
Received: 15 January 2014 Accepted: 4 April 2014

Published: 13 April 2014

\section{References}

1. Nardoni S, Angelici M, Mugnaini L, Mancianti F: Prevalence of Toxoplasma gondii infection in Myocastor coypus in a protected Italian wetland. Parasit Vectors 2011, 4:240.

2. Raizman RE, Neva FA: Detection of circulating antigen in acute experimental infections with Toxoplasma gondii. Infect Dis 1975, 132:44-48.

3. Abu-Madi MA, Naema Al-Molawi N, Behnke JM: Seroprevalence and epidemiological correlates of Toxoplasma gondii infections among patients referred for hospital-based serological testing in Doha Qatar. Parasit Vectors 2008, 1:39.

4. Alvarado-Esquivel C, Torres-Berumen JL, Estrada-Martínez S, Liesenfeld O, Mercado-Suarez MF: Toxoplasma gondii infection and liver disease: a case-control study in a northern Mexican population. Parasit Vectors 2011, 4:75.

5. Zhou P, Chen Z, Li HL, Zheng H, He S, Lin RQ, Zhu XQ: Toxoplasma gondii infection in humans in China. Parasit Vectors 2011, 4:165.

6. Boughattas S, Bergaoui R, Essid R, Aoun K, Bouratbine A: Seroprevalence of Toxoplasma gondii infection among horses in Tunisia. Parasit Vectors 2011, 4:218

7. Wang $M$, Wang $Y H$, Ye Q, Meng P, Yin H, Zhang DL: Serological survey of Toxoplasma gondii in Tibetan mastiffs (Canislupus familiaris) and yaks (Bos grunniens) in Qinghai China. Parasit Vectors 2012, 5:35.

8. Yang N, Mu MY, Li HK, Long M, He JB: Seroprevalence of Toxoplasma gondii infection in slaughtered chickens, ducks, and geese in Shenyang, northeastern China. Parasit Vectors 2012, 5:237.

9. Mévélec MN, Bout D, Desolme B, Marchand $H$, Magné $R$, Bruneel $O$, Buzoni-Gatel D: Evaluation of protective effect of DNA vaccination with genes encoding antigens GRA4 and SAG1 associated with GM-CSF plasmid, against acute, chronical and congenital toxoplasmosis in mice. Vaccine 2005, 23:4489-4499.

10. Dubey JP, Weigel RM, Siegel AM, Thulliez P, Kitron UD, Mitchell MA Mannelli A, Mateus-Pinilla NE, Shen SK, Kwok OC, Todd KS: Sources and reservoirs of Toxoplasma gondii infection on 47 swine farms in Illinois. J Parasitol 1995, 81:723-729.

11. Velge-Roussel F, Chardès T, Mévélec P, Brillard M, Hoebeke J, Bout D: Epitopic analysis of the Toxoplasma gondii major surface antigen SAG1. Mol Biochem Parasit 1994, 66:31-38.

12. Debard N, Buzoni-Gatel D, Bout D: Intranasal immunization with SAG1 protein of Toxoplasma gondii in association with cholera toxin dramatically reduces development of cerebral cysts after oral infection. Infect Immun 1996, 64:2158-2166.

13. Bulow R, Boot hroyd JC: Protection of mice from fatal Toxoplasma gondi infection by immunization with P30 antigen in liposomes. J Immunol 1991, 147:3496-3500.

14. Petersen E, Nielsen HV, Christiansen L, Spenter J: Immunization with E. coli produced recombinant T. gondii SAG1 with alum as adjuvant protect mice against lethal infection with Toxoplasma gondii. Vaccine 1998, 16:1283-1289

15. Biemans R, Gregoire D, Haumont M, Bosseloir A, Garcia L, Jacquet A, Dubeaux C, Bollen A: The conformation of purified Toxoplasma gondii SAG1 antigen, secreted from engineered Pichia pastoris, is adequate for serorecognition and cell proliferation. J Biotechnol 1998, 66:137-146.

16. Darcy F, Maes P, Gras-Masse H, Auriault C, Bossus M, Deslee D, Godard I, Cesbron MF, Tartar A, Capron A: Protection of mice and nude rats against toxoplasmosis by a multiple antigenic peptide construction derived from Toxoplasma gondii P30 antigen. J Immunol 1992, 149:3636-3641.

17. Godard I, Estaquier J, Zenner L, Bossus M, Auriault C, Darcy F, Gras-Masse H, Capron A: Antigenicity and immunogenicity of P30-derived peptides in experimental models of toxoplasmosis. Mol Immunol 1994, 31:1353-1363.

18. Velge-Roussel F, Dimier-Poisson I, Buzoni-Gatel D, Bout D: Anti-SAG1 peptide antibodies inhibit the penetration of Toxoplasma gondii tachyzoites into enterocyte cell lines. Parasitol 2001, 123:571-578.

19. Khan IA, Ely KH, Kasper LH: A purified parasite antigen (P30) mediates CD8+ T cell immunity against fatal Toxoplasma gondii infection in mice. J Immunol 1991, 147:3501-3506.

20. Handman E, Goding JW, Remington JS: Detection and characterization of membrane antigen of Toxoplasma gondii. Immunol 1980, 124:2578-2583.
21. Kasper $\mathrm{LH}$, Crabb JH, Pfefferkorn ER: Purification of a major membrane protein of Toxoplasma gondii by immunoabsorption with a monoclonal antibody. J Immunol 1983, 130:2407-2412.

22. Burg $\mathrm{J}$, Perelman D, Kasper $\mathrm{LH}$, Ware $\mathrm{PL}$, Boothroyd JC: Molecular analysis of the gene encoding the major surface antigen of Toxoplasma gondii. Immunol 1988, 141:3584-3591.

23. Soldati D, Boothroyd JC: A selector of transcription initiation in the protozoan the protozoan parasite Toxoplasma gondii. Mol Cell Biol 1995, 15:87-93.

24. Windeck T, Gross U: Toxoplasma gondii strain specific transcript level of SAG1 and their association with virulence. Parasitol Res 1996, 82:715-719.

25. Nam HW, Im KS, Baek EJ, Choi WY, Cho SY: Analysis of antigenic domain of GST fused major surface protein (p30) fragments of Toxoplasma gondii. Korean J Parasitol 1996, 34:135-141.

26. Johnson Alan M, McDonald PJ, Neoh SH: Molecular weight analysis of soluble antigens from Toxoplasma gondii. J Parasitol 1983, 69:459-464.

27. Mineo JR, McLeod R, Mack D, Smith J, Khan IA, Ely KH, Kasper LH: Antibodies to Toxoplosma gondii major surface protein (SAG1-P30) inhibit infection of host cells and are produced in murine intestine after peroral infection. J Immunol 1993, 150:3951-3964.

28. Mineo JR, Kasper LH: Attachment of Toxoplasma gondii to host cell involves major surface protein, SAG-1(P30). Exp Parasitol 1994, 79:11-20.

29. Grimwood J, Smith JE: Toxoplasma gondii:The role of parasite and secreted proteins in host cell invasion. Int J Parasitol 1996, 26:169-1173.

30. Li XR, Wang YH, Zhao XZ, Zhang DL: Update on host cell invasion by Toxoplasma gondii. Chin J Parasitol 2007, 25:154-158.

31. Robinson SA, Smith JE, Millner PA: Toxoplasma gondii major surface antigen (SAG1): in vitro analysis of host cell binding. Parasitol 2004 128:391-396.

32. Tomavo S: The major surface proteins of Toxoplasma gondii structures and functions. Curr Top Mcrobiol 1996, 219:45-54.

33. Cesbron-Delauw MF, Tomavo S, Beauchamps P, Fourmaux MP, Camus D, Capron A, Dubremetz JF: Similarities between the primary structures of two distinct major surface proteins of Toxoplasma gondii. J Biol Chem 1994, 269:16217-16222.

34. Howe DK, Summers BC, Sibley LD: Acute virulence in mice is associated with markers on chromosome VIII in Toxoplasma gondii. Infect Immun 1996, 64:5193-5198.

35. Lekutis C, Ferguson DJ, Grigg ME, Camps M, Boothroyd JC: Surface antigens of Toxoplasma gondii: variations on the theme. Int J Parasitol 2001, 31:1285-1292.

36. Wu YZ, Zhu XH: The Cognition and understanding for study on epitopic biology. Cur Immunol 1998, 18:1-2.

37. Beghetto E, Spadoni A, Buffolano W, Del Pezzo M, Minenkova O, Pavoni E, Pucci A, Cortese R, Felici F, Gargano N: Molecular dissection of the human B-cell response against Toxoplasma gondii infection by lambda display of cDNA libraries. Int J Parasitol 2003, 33:163-173.

38. Siachoque H, Guzman F, Burgos J, Patarroyo ME, Gomez Marin JE: Toxoplasma gondii: immunogenicity and protection by $\mathrm{P} 30$ peptides in a murine model. Exp Parasitol 2006, 114:62-65.

39. Kato M, Claveria FG, Maki Y, Sanda K, Tanaka T, Omata Y, Nagasawa H, Suzuki N: Reactivity of synthetic SAG1 (p30) peptide sequences with RH, S273 and beverley strain-induced anti-Toxoplasma gondii antibodies. Pathobiol 2007, 74:50-56

40. Cardona N, De-la-Torre A, Siachoque H, Patarroyo MA, Gomez-Marin JE: Toxoplasma gondii: P30 peptides recognition pattern in human toxoplasmosis. Exp Parasitol 2009, 123:199-202.

41. Wang $Y H$, Wang GX, Zhang DL, Yin H, Wang M: Screening and identification of novel B cell epitopes of Toxoplasma gondii SAG1. Parasit Vectors 2013, 6:125

42. Gazzinelli RT, Hakim FT, Hieny S, Shearer GM, Sher A: Synergistic role of CD4+ and CD8+ T lymphocytes in IFN-gamma production and protective immunity induced by an attenuated Toxoplasma gondii. Vaccine 1991, 146:286-292.

43. Kang H, Remington JS, Suzuki Y: Decreased resistance of B cell-deficient mice to infection with Toxoplasma gondii despite unimpaired expression of IFN-gamma, TNF-alpha, and inducible nitric oxide synthase. J Immunol 2000, 164:2629-2634

44. Schaap D, Vermeulen AN, Roberts CW, Alexander J: Vaccination against toxoplasmosis: current status and future prospects. In Toxoplasma gondii: 
the model apicomplexan perspectives and methods. 1st edition. Edited by Weiss LM, Kim K. London: Academic Press; 2007:731-736.

45. Kasper $\mathrm{LH}$, Khan IA: Role of $P 30$ in host immunity and pathogenesis of T. gondii infection. Res Immunol 1993, 144:45-48.

46. Rachinel N, Buzoni-Gatel D, Dutta C: The induction of acute ileitis by a single microbial antigen of Toxoplasma gondii. J Immunol 2004, 173:2725-2735.

47. Makioka A: Expression of the major surface antigen of Toxoplasma gondii as in soluable glutathione Stransferase fusion. Jpn J Parasitol 1991, 40:344.

48. Letscher-Bru V, Pfaff AW, Abou-Bacar A, Filisetti D, Antoni E, Villard O, Klein JP, Candolfi E: Vaccination with Toxoplasma gondii SAG-1 protein is protective against congenital toxoplasmosis in BALB/c mice but not in CBA/J mice. Infect Immun 2003, 71:6615-6619.

49. Chuang SC, Ko JC, Chen CP, Du JT, Yang CD: Induction of long-lasting protective immunity against Toxoplasma gondii in BALB/c mice by recombinant surface antigen 1 protein encapsulated in poly (lactide-co-glycolide) microparticles. Parasit Vectors 2013, 6:34.

50. Cong H, Gu QM, Jiang Y, He SY, Zhou HY, Yang T, Li Y, Zhao QL: Oral immunization with a live recombinant attenuated Salmonella typhimurium protects mice against Toxoplasma gondii. Parasite Immuno 2005, 27:29-35.

51. Yiang Z, Ertl HC: Manipulation of the immune response to a plasmidoncoded viral antigen by coinoculation with plasmids expressing cytokines. Immunity 1995, 2:129-1351.

52. Zhao G, Zhou A, Lu G, Meng M, Sun M, Bai Y, Han Y, Wang L, Zhou H, Cong $H$, Zhao Q, Zhu XQ, He S: Identification and characterization of Toxoplasma gondii aspartic protease 1 as a novel vaccine candidate against toxoplasmosis. Parasit Vectors 2013, 6:175.

53. Saito S, Aosai F, Rikihisa N, Mun HS, Norose K, Chen M, Kuroki T, Asano T, Ochiai T, Hata H, Ichinose M, Yano A: Establishment of gene vaccinated skin grafting against Toxoplasma gondii infection in mice. Vaccine 2001, 19:2172-2180

54. Nielsen HV, Lauemøller SL, Christiansen L, Buus S, Fomsgaard A, Petersen E: Complete protection against lethal Toxoplasma gondii infection in mice immunized with a plasmid encoding the SAG1 gene. Infect Immun 1999, 67:6358.

55. Seder RA, Paul WE: Acquisition of lymphokine-producing phenotype by CD4+ T cells. Annu Rev Immunol 1994, 12:635-637.

56. Ivory $C$, Chadee K: DNA vaccines: designing strategies against parasitic infections. Genet Vaccines Ther 2004, 2:17-25.

57. Cong $H$, Yuan Q, Zhao Q, Zhao LX, Yin HQ, Zhou HY, He SY, Wang ZY: Comparative efficacy of a multi-epitope DNA vaccine via intranasal, peroral, and intramuscular delivery against lethal Toxoplasma gondii infection in mice. Parasit Vectors 2014, 7:145

58. Fachado A, Rodriguez A, Angel SO, Pinto DC, Vila I, Acosta A, Amendoeira RR, Lannes-Vieira J: Protective effect of a naked DNA vaccine cocktail against lethal toxoplasmosis in mice. Vaccine 2003, 21:1327-1335.

59. Cong H, Gu QM, Yin HE, Wang JW, Zhao QL, Zhou HY, Li Y, Zhang JQ: Multi-epitope DNA vaccine linked to the A2/B subunit of cholera toxin protectmice against Toxoplasma gondii. Vaccine 2008, 26:3913-3921.

60. Xue M, He S, Cui Y, Yao Y, Wang H: Evaluation of the immune response elicited by multi-antigenic DNA vaccine expressing SAG1, ROP2 and GRA2 against Toxoplasma gondii. Parasitol Int 2008, 57:424-429.

61. Wang Y, Wang M, Wang G, Pang A, Fu B, Yin H, Zhang D: Increased survival time in mice vaccinated with a branched lysine multiple antigenic peptide containing B- and T-cell epitopes from T. gondii antigens. Vaccine 2011, 29:8619-8623.

62. Meng M, He S, Zhao G, Bai Y, Zhou H, Cong H, Lu G, Zhao Q, Zhu XQ: Evaluation of protective immune responses induced by DNA vaccines encoding Toxoplasma gondii surface antigen 1 (SAG1) and 14-3-3 protein in BALB/c mice. Parasit Vectors 2012, 5:273.

63. Cong $\mathrm{H}$, Zhang $M$, Xin Q, Wang Z, Li Y, Zhao Q, Zhou H, He S: Compound DNA vaccine encoding SAG1/SAG3 with $A 2 / B$ subunit of cholera toxin as a genetic adjuvant protects BALB/C mice against Toxoplasma gondii. Parasit Vectors 2013, 6:63

64. Haumont M, Delhaye L, Garcia L, Jurado M, Mazzu P, Daminet V, Verlant V, Bollen A, Biemans $R$, Jacquet A: Protective immunity against congenital toxoplasmosis with recombinant SAG1 protein in a guinea pig model. Infect Immun 2000, 68:4948-4953.

65. Daryani A, Hosseine AZ, Dalimi A: Immune response against excreted/ secreted antigens of Toxoplasma gondii tachyzoites in the murine model. Vet Parasitol 2003, 113:123-134.
66. Hiramoto RM, Galisteo AJ, Do Nascimento N, De Andrade HF: 200Gy sterilized Toxoplasma gondii tachyzoites maintain metabolic functions and mammalian cell invasion, eliciting cellular immunity and cytokine response similar to natural infection in mice. Vaccine 2002, 20:2072-2081.

67. Glor SB, Edelhofer R, Grimm F, Deplazes P, Basso W: Evaluation of a commercial ELISA kit for detection of antibodies against Toxoplasma gondii in serum, plasma and meat juice from experimentally and naturally infected sheep. Parasit Vectors 2013, 6:85.

68. Tian YM, Dai FY, Huang SY, Deng ZH, Duan G, Zhou DH, Yang JF, Weng YB, Zhu XQ, Zou FC: First report of Toxoplasma gondii seroprevalence in peafowls in Yunnan Province, Southwestern China. Parasit Vectors 2012, 5:205.

69. Walle F, Kebede N, Tsegaye A, Kassa T: Seroprevalence and risk factors for Toxoplasmosis in HIV infected and non-infected individuals in Bahir Dar, Northwest Ethiopia. Parasit Vectors 2013, 6:15.

70. Dupouy-Camet J, de Souza SL, Maslo C, Paugam A, Saimot AG, Benarous R, Tourte-Schaefer C, Derouin F: Detection of Toxoplasma gondii in venous blood from AIDS patients by polymerase chain reaction. J Clin Microbiol 1993, 31:1866-1869.

71. Khalifa KES, Roth A, Roth B, Arasteh KN, Janitschke K: Value of PCR for evaluating occurrence of parasitemia in immunocompromised patients with cerebral and extracerebral toxoplasmosis. J Clin Microbiol 1994, 32:2813-2819.

72. Sun X, Lu H, Jia B, Chang Z, Peng S, Yin J, Chen Q, Jiang N: A comparative study of Toxoplasma gondii seroprevalence in three healthy Chinese populations detected using native and recombinant antigens. Parasit Vectors $2013,6: 241$

73. Taylor DW, Evans CB, Aley SB, Barta JR, Danforth HD: Identification of an apically-located antigen that is conserved in sporozoan parasites. Proc Natl Acad Sci U S A 1990, 37:540-545.

74. Hassl A, Muller WA, Aspock H: An identical epitope in Pneumocystis carinii and Toxoplasma gondii causing serological cross reactions. Parasitol Res 1991, 77:351-352.

75. Hofgärtner WT, Swanzy SR, Bacina RM, Condon J, Gupta M, Matlock PE, Bergeron DL, Plorde JJ, Fritsche TR: Detection of immunoglobulin G (lgG) and IgM antibodies to Toxoplasma gondii: evaluation of four commercial immunoassay systems. J Clin Microbiol 1997, 35:3313-3315.

76. Beghetto E, Spadoni A, Bruno L, Buffolano W, Gargano N: Chimeric antigens of Toxoplasma gondii: toward Standardization of toxoplasmosis serodiagnosis using recombinant products. J Clin Microbiol 2006, 44:2133-2140.

77. Harning D, Spenter J, Metsis A, Vuust J, Petersen E: Recombinant Toxoplasma gondii surface antigen 1 (P30) expressed in Escherichia coli is recognized by human Toxoplasma-specific immunoglobulin M (IgM) and IgG antibodies. Clin Diagn Lab Immunol 1996, 3:355-357.

78. Chen XG, Gong Y, Hua-Li, Lun ZR, Fung MC: High-level expression and purification of immunogenic recombinant SAG1 (P30) of Toxoplasma gondii in Escherichia coli. Protein Expr Purif 2001, 23:33-37.

79. Wu K, Chen XG, Li H, Yan H, Yang PL, Lun ZR, Zhu XQ: Diagnosis of human toxoplasmosis by using the recombinant truncated surface antigen 1 of Toxoplasma gondii. Diagn Microbiol Infect Dis 2009, 64:261-266.

80. Dai JF, Jiang M, Wang YY, Qu LL, Gong RJ, Si J: Evaluation of a recombinant multiepitope peptide for serodiagnosis of Toxoplasma gondii infection. Clin Vaccine Immunol 2012, 19:338-342.

81. Grover CM, Thulliez P, Remington JS, Boothroyd JC: Rapid prenatal diagnosis of congenital Toxoplasma infection by using polymerase chain reaction and amniotic fluid. J Clin Microbiol 1990, 28:2297-2301.

82. Bretagne S, Costa JM, Vidaud M, Tran J, Nhieu V, Fleury-Feith J: Detection of Toxoplasma gondii by competitive DNA amplification of bronchoalveolar lavage samples. J Infect Dis 1993, 168:1585-1588.

83. Homan WL, Vercammen $\mathrm{M}$, De Braekeleer J, Verschueren $\mathrm{H}$ : Identification of a 200- to 300-fold repetitive 529 bp DNA fragment in Toxoplasma gondii, and its use for diagnostic and quantitative PCR. Int J Parasitol 2000, 30:69-75.

84. Reischl U, Bretagne S, Kruger D, Ernault P, Costa JM: Comparison of two DNA targets for the diagnosis of toxoplasmosis by real-time PCR using fluorescence resonance energy transfer hybridization probes. BMC Infect Dis 2003, 3:7.

85. Costaa JM, Bretagnea S: Variation of B1 gene and AF146527 repeat element copy numbers according to Toxoplasma gondii strains assessed using real-time quantitative PCR. J Clin Microbiol 2012, 50:1452-1454. 
86. Contini C, Cultrera R, Seraceni $S$, Segala D, Romani R, Fainardi E, Cinque $P$, Lazzarin A, Delia S: The role of stage specific oligonucleotide primers in providing effective laboratory support for the molecular diagnosis of reactivated Toxoplasma gondii encephalitis in patients with AIDS. J Med Microbiol 2002, 51:879-890.

87. Savva D, Morris JC, Johnson JD, Holliman RE: Polymerase chain reaction for detection of Toxoplasma gondii. J Med Microbiol 1990, 31:25-31.

88. Holliman R, Johnson J, Savva D, Cary N, Wreghitt T: Diagnosis of Toxoplasma gondii in cardiac transplant recipients using the polymerase chain reaction. Clin Pathol 1992, 45:931-932.

89. Notomi T, Okayama H, Masubuchi H, Yonekawa T, Watanabe K, Amino N, Hase T: Loop-mediated isothermal amplification of DNA. Nucleic Acids Res 2000, 28:е63.

90. Thekisoe OMM, Bazie RSB, Coronel-Servian AM, Sugimoto C, Kawazu S, Inoue N: Stability of loop-mediated isothermal amplification (LAMP) reagents and its amplification efficiency on crude trypanosome DNA templates. J Vet Med Sci 2009, 71:471-475.

91. Krasteva D, Toubiana M, Hartati S, Kusumawati A, Dubremetz JF, Widada JS: Development of loop-mediated isothermal amplification (LAMP) as a diagnostic tool of toxoplasmosis. Vet Parasitol 2009, 162:327-331.

92. Lau YL, Meganathan P, Sonaimuthu P, Thiruvengadam G, Nissapatorn V, Chen Y: Specific, sensitive, and rapid diagnosis of active toxoplasmosis by a loop-mediated isothermal amplification method using blood samples from patients. J Clin Microbiol 2010, 48:3698-3702.

93. Kong QM, Lu SH, Tong QB, Lou D, Chen R, Zheng B, Kumagai T, Wen LY, Ohta N, Zhou XN: Loop-mediated isothermal amplification (LAMP): Early detection of Toxoplasma gondii infection in mice. Parasit Vectors 2012, 5:2.

doi:10.1186/1756-3305-7-180

Cite this article as: Wang and Yin: Research progress on surface antigen 1 (SAG1) of Toxoplasma gondii. Parasites \& Vectors 2014 7:180.

\section{Submit your next manuscript to BioMed Central and take full advantage of:}

- Convenient online submission

- Thorough peer review

- No space constraints or color figure charges

- Immediate publication on acceptance

- Inclusion in PubMed, CAS, Scopus and Google Scholar

- Research which is freely available for redistribution 